\title{
Memórias de Anzac: colocando em prática a teoria da memória popular na Austrália*
}

\author{
Alistair Thomson** \\ Tradução de André C. Gattaz \\ e Meire T. M. Soares ${ }^{\star * *}$
}

De ACORDO COM A "LENDA DO $A N Z A C$ ", durante a Grande Guerra de 1914 a 1918, os soldados australianos provaram a si mesmos e ao resto do mundo que a nova raça de homens anglo-celtas do sul tinha o valor equivalente aos homens das demais nações do mundo. Galipoli, onde pela primeira vez os australianos entraram em batalha, em 25 de abril de 1915, foi vista como o batismo de fogo da nova Commonwealth australiana. A comemoração do Dia do An₹ac, em 25 de abril a cada ano, tornou-se o equivalente australiano do dia da Independência Norteamericana ou do dia da Tomada da Bastilha na França (sem os tons revolucionários).

\footnotetext{
* Artigo publicado originalmente em Oral History, vol. 18, número 2. p. 25-31. Tradução autorizada pela Oral History Society.

* Conferencista do Centro de Educação Continuada da Universidade de Sussex.

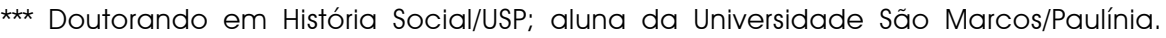

1 Anzac é a abreviação de Australian and New Zealand Army Corps (Corpo do Exército Autraliano e Neo-Zelandês), embora os Neo-Zelandeses sejam normalmente excluídos da lenda australiana. Neste texto. o termo refere-se tanto ao Corpo do Exército como aos seus ex-membros.
} 
Este artigo enfoca a vida e as memórias de Fred Farraw, um dos vinte veteranos da Grande Guerra, provenientes das classes operárias de Melbourne, a quem entrevistei ${ }^{2}$. [...] Eu não afirmo aqui que Fred Farraw fosse um típico 'digger' (nome dado aos soldados australianos e neozelandeses na Guerra de 1914-18), longe disso. A busca obsessiva em definir o caráter nacional tem sido um dos objetivos malogrados da historiografia australiana, portanto neste artigo não pretendo analisar em que medida a lenda do Anz̧a é uma representação acurada do "típico" soldado australiano. Estou mais interessado nas interações entre os estereótipos da lenda do Anzac e as identidades individuais dos soldados, na experiência da diferença assim como da semelhança, e nas maneiras pelas quais o "típico" pode ser opressivo. Eu quero avaliar a relação entre a memória de guerra de Fred Farraw e a mitologia nacional que publicamente define a sua experiência como soldado, e usar seu estudo de caso para dar sentido à relação geral entre a memória individual e o mito coletivo.

A teoria da memória (e do mito nacional) que instrui este ensaio foi desenvolvida pelo Grupo de Memória Popular do Centro de Estudos Culturais Contemporâneos de Birmingham. O grupo baseouse nas interações entre as memórias privadas e públicas, usando a seguinte abordagem para definir a memória individual: compomos nossas memórias para dar sentido à nossa vida passada e presente. "Composure" (composição) é o termo apropriadamente ambíguo usado pelo Grupo de Memória Popular para descrever o processo de elaboração da memória. Por um lado, "compomos" (compose) ou construímos memórias usando a linguagem e significados públicos da nossa cultura. Por outro, compomos memórias que ajudem a nos sentirmos relativamente confortáveis com nossas vidas e que nos dêem um sentimento de serenidade (composure). Reelaboramos ou reprimimos memórias de experiências que ainda são dolorosas e "perigosas" porque elas não se ajustam facilmente à nossa identidade atual, ou porque seus traumas e tensões inerentes nunca foram plenamente resolvidos.

2 As entrevistas com Fred Farraw foram gravadas em julho de 1983 e abril de 1987, e as fitas e transcrições das entrevistas, junto com as outras fitas e transcrições do projeto, estão disponíveis na coleção da biblioteca do Australian War Memorial. 
Buscamos a tranqüilidade, o alinhamento de nossas vidas passadas, presente e futura.

Uma conexão teórica fundamental, elo entre os dois sentidos de composure, é que o processo aparentemente privado de compor memórias seguras é na realidade muito público. As nossas memórias são perigosas e dolorosas se não estiverem de acordo com as normas ou versões públicas do passado. Compomos nossas memórias de forma que se ajustem ao que é publicamente aceitável - ou, se formos excluídos da aceitação pública geral, buscamos públicos restritos que afirmem nossas identidades e reconheçam a maneira pela qual queremos lembrar nossas vidas ${ }^{3}$.

Alguns críticos da história oral argumentam que o fato de compormos nossas memórias invalida seu uso pelos historiadores. Isto pode ser verdadeiro para os oralistas que usam a memória como uma fonte literal do que aconteceu no passado. Mas se nós também estivermos interessados, como devemos estar, na maneira como o passado repercute em nossa vida atual, então o testemunho oral é uma evidência essencial para a análise das interações entre passado e presente, entre memória e mitologia.

Essa abordagem da memória requer uma revisão da técnica de entrevista. Em minhas entrevistas iniciais com veteranos de guerra de Melbourne, nas quais eu queria ver como as experiências dos soldados provenientes da classe operária contrastavam com a lenda do Anzac, usei uma abordagem de história de vida cronológica como base para as questões. As entrevistas revelaram muitas diferenças entre suas vidas e a lenda, mas o que mais me chocou foi observar a intensidade do envolvimento das memórias com o mito. Alguns homens, por exemplo, relataram cenas do filme Galipoli como se fossem de suas próprias vidas. Guiado pelas idéias do Grupo de Memória Popular, portanto, elaborei uma nova abordagem para uma segunda rodada de entrevistas com alguns dos mesmos homens. Nas novas entrevistas procurei descobrir como cada homem compunha e exprimia a suas memórias, explorando quatro interações-chave, entre: público e privado; passado e presente; memória e identidade; entrevistador e entrevistado. As informações

\footnotetext{
3 Ver "Popular Memory: Theory, Politics, Method", (Johnson et al., 1982).
} 
pessoais que eu havia obtido nas primeiras entrevistas tornou possível adequar minhas questões especificamente a cada homem, considerando suas memórias e identidades particulares. Se eu não tivesse realizado as entrevistas originais, teria de integrar a abordagem de história de vida às novas perspectivas.

Para investigar a relação entre memórias públicas e privadas, escolhi o mito público como ponto de partida para as seguintes questões: Qual foi sua reação aos vários filmes e livros de guerra, antigos e atuais, assim como ao Dia do Anzac e aos memoriais de guerra? Eles representam bem as suas próprias experiências? Como eles o fazem se sentir? Nós também enfocamos características específicas da lenda: Havia um caráter próprio do Anzac distintivo? Em que medida este caráter era verdadeiro em relação à sua própria natureza e experiência? Vocês eram muito diferentes dos soldados dos outros exércitos? Pedi a cada homem que definisse certas palavras-chave em seus próprios termos - 'digger', 'camaradagem', 'o espírito do Anzac' - e descobri que alguns homens, que aparentemente eram acríticos quanto à lenda, tinham compreensões contrárias e mesmo contraditórias sobre seus principais termos.

Outra sessão de discussão enfocou a experiência e a identidade pessoal: Como você se sente em relação às suas ações nos principais momentos (alistamento, combates, retorno)? Quais eram suas ansiedades e incertezas? Que sentido você atribui às suas experiências e como outras pessoas definem você? O quanto você se sentia incluído ou excluído? O que era comportamento aceitável e inaceitável (o que não era "viril")? Como e por que alguns homens caíram no ostracismo? É claro que essas memórias, e a respectiva composição da memória, mudaram através do tempo (em função da interação passado-presente), assim discutimos como os eventos pós-guerra - como o retorno, a depressão, a segunda guerra mundial, mudanças domésticas, a terceira idade e o renascimento da lenda do Anzac nos anos 80 - afetaram a identidade e a memória. A nova abordagem das entrevistas mostrou-me que o modo como lembramos e articulamos nossas recordações muda através do tempo, indicando como isto pode ser relacionado com mudanças na percepção pública.

Outro difícil foco de atenção das novas entrevistas refere-se à maneira como as memórias são afetadas pelas estratégias de contenção, 
pelos meios de controle da frustração, fracasso, perda ou dor. Isto exigiu um balanço sensível entre uma investigação potencialmente dolorosa e a leitura das entrelinhas da memória. O que é possível ou impossível lembrar, ou mesmo ser dito em voz alta? Quais são os significados ocultos dos silêncios e súbitas mudanças de assunto? O que está contido em uma história "fixa"? Sentimentos e experiências profundamente reprimidos podem ser descartados em formas menos conscientes de expressão, em sonhos passados e presentes, em lapsos freudianos, na linguagem corporal e mesmo no humor, que muitas vezes é usado para superar ou esconder a perturbação e a dor. A discussão do conteúdo simbólico e dos sentimentos expressos pelos sonhos de guerra relatados sugeriu um novo entendimento do impacto da guerra no indivíduo e do que não poderia ser expresso publicamente. Por outro lado, minhas anotações no decorrer das entrevista sobre expressões faciais, movimentos corporais e modo de falar revelavam certos significados emotivos das memórias que não poderiam transparecer nas transcrições das entrevistas.

Esta abordagem levantou dilemas éticos para mim como oralista. A entrevista que se aproxima de uma relação terapêutica pode ser prejudicial para o entrevistado, assim como compensadora para o entrevistador. Isso requer grande cuidado, sensibilidade e obediência à regra básica de que o bem-estar do entrevistado sempre antecede os interesses da pesquisa. Às vezes eu tinha de interromper uma linha de questionamento em uma entrevista, ou era solicitado a parar, porque isso era muito doloroso para o entrevistado. Ao contrário do terapeuta, como oralista eu não estaria por perto para ajudar o depente a unir os pedaços de memórias que eram perturbadores.

Uma resposta parcial era tornar a entrevista e a relação com o entrevistado um processo mais aberto. Eu tentava discutir como minhas questões afetavam as rememorações, e aquilo que era difícil de ser relatado a mim. Para encorajar o diálogo ao invés do monólogo, eu falava sobre meus próprios interesses e meu papel como pesquisador. De alguma forma, esta mudança em meu posicionamento (limitada pelo fato de que eu nunca abdiquei, realmente, de meu papel como entrevistador), afetava o ato de lembrar. Às vezes isso encorajava um dos homens a abrir-se comigo e reconsiderar aspectos de sua vida, embora outros resistissem a esta oportunidade. A introdução explícita de minhas 
atitudes nas entrevistas deve ter estimulado alguns homens a contar histórias apenas para a minha aprovação, embora normalmente eu sentisse que isso facilitava a discussão e provocava tanto discordâncias quanto concordâncias. No caso de Fred Farraw, isso não era uma questão muito importante, pois quando nós nos encontramos, sua memória da guerra já estava relativamente fixada. Apesar de termos desenvolvido, através dos anos, uma relação próxima e de confiança, na qual as lembranças de Fred eram ativamente encorajadas pelo meu interesse, ele parecia contar sempre as mesmas histórias, da mesma forma, às suas várias audiências - incluindo a mim. A história de guerra de Fred, entretanto, não permaneceu sempre tão fixa. Gradualmente percebi que sua memória da guerra e sua identidade como ex-membro das forças armadas passaram por três fases distintas, moldadas pela relação mutável entre os significados do Anzac e sua própria identidade subjetiva.

Nascido em 1897, Fred Farraw cresceu numa pequena fazenda na zona rural de New South Wales. Ele não gostava do trabalho agrícola e, inspirado pelo fervor patriótico que varreu o país depois do desembarque de Galipoli, ficou feliz em juntar-se à "Marcha Cangurú" - formada por recrutas rurais da Força Imperial Australiana $(A I F)$. Ele se alistou em um batalhão de infantaria e foi mandado para a França e o Somme em 1916. Em sua própria avaliação, Fred não era um grande soldado. Ele era muito jovem, ingênuo e pouco confiante, e não era muito apto para lutar e matar. Assim como muitos outros soldados de outras nacionalidades, ele se aterrorizava com as batalhas e sentia-se infeliz nas trincheiras, começando a duvidar de seu próprio valor e da própria guerra. Seus melhores companheiros foram mortos e mutilados ao seu lado, e embora Fred tenha sobrevivido, seu estado físico e emocional ficou destroçado:

"Quando voltei para casa, fiquei seis meses no hospital Randwick para ver o que eles podiam fazer para melhorar as condições dos meus pés, além do meu reumatismo e de uma complicação nasal que eu contraí em Somme... Eu não percebia isso naquele tempo, mas depois passei a compreender. Eu tinha neurose de guerra, que ainda não era reconhecida como tal naqueles dias, então eu tive que me arranjar sozinho. Isso realmente desenvolveu em mim um grande com- 
plexo de inferioridade! Eu me sentia extremamente mal... Bem, eu tinha atingido tal estágio nesse processo, que quando eu queria falar sobre aquilo, não encontrava uma maneira de fazê-lo. Eu começava a gaguejar e parecia que dentro de mim tudo tinha dado um nó - foi assim por anos e anos."

Da posição afortunada e retrospectiva de um sobrevivente que superou sua neurose, Fred atribui a sua condição de neurótico de guerra ao efeito dos constantes bombardeios do Somme. Ele admite ter sido incapaz de expressar seu medo durante e após a batalha, sendo constantemente desencorajado a fazê-lo: isso não era viril nem australiano. Muitas das histórias de Fred comparam sua inadequação à suposta coragem dos outros australianos. A lenda do soldado australiano - o melhor lutador da guerra - fez com que muitos diggers reprimissem seus sentimentos, piorando o trauma psicológico da guerra.

A condição de Fred e seu sentimento de inadequação pessoal pioraram após seu retorno à Austrália:

"Eu parecia como um cão ou gato de estimação abandonado nas montanhas de Dandenong (uma cadeia de montanhas perto de Melbourne). Se alguém me perguntasse agora como eu me sentia naquele tempo, eu diria que em muitos aspectos - e eu suponho que isso se aplicava a muitos outros, muitos outros - nós nos sentíamos como se não valêssemos absolutamente nada. Em outras palavras: não éramos mais os mesmos de quando partimos para a Guerra. Não sei se você já ouviu as canções de Eric Bogle; ele mencionou isso em uma canção que fez sobre o Vietnã. Então, quando voltei à vida civil, isso era algo novo e, em grande medida, aterrador. Você é jogado em um mundo frio e duro. Ninguém mais se preocupa com você. Você tem que conseguir seu próprio abrigo, seu próprio alimento. Em resumo, você tem de se defender sozinho."

Para homens como Fred, que eram adolescentes quando se alistaram, a experiência social da repatriação foi especialmente traumática. Fred até que teve sorte. Devido à sua saúde comprometida, ele não podia voltar a trabalhar na fazenda da família, mas uma prima e seu 
marido digger deram-lhe um quarto em sua casa em Sydney e ajudaramno em sua recuperação. Ele se alistou em um projeto de treinamento vocacional do governo para tornar-se estofador, mas o projeto não foi bem organizado, e apesar do governo inicialmente subsidiar os salários dos estagiários, os empregadores não se interessaram por eles quando o subsídio terminou. Fred procurou emprego por quase dois anos até conseguir um trabalho em uma fábrica de motores automotivos. Perguntei-lhe se seu distintivo de veterano de guerra ajudou-o a conseguir um emprego. Não ajudou, e ele não o usaria por muitos anos:

“- Bom, nós não dávamos valor a isso.

- Por quê?

- Bem, é difícil explicar, a não ser porque nós estávamos desiludidos. Tudo o que nos falaram a respeito da guerra, não se confirmou. Falaram que quando a guerra terminasse, o governo nos retribuiria pelo que havíamos feito, isso também não funcionou.

- Como assim?

- Bem, veja, nos anos 20, a não ser que você tivesse perdido um braço, uma perna ou qualquer coisa assim, era tão difícil conseguir uma pensão como ganhar na loteria. Não havia o reconhecimento da neurose e de outras complicações da guerra... E de qualquer forma, os médicos daquele tempo tratavam os diggers nas entrevistas e nos exames como se fossem cidadãos de quinta categoria, como se fôssemos aborígines. Havia muita hostilidade entre os diggers e os oficiais de repatriação.”

Fred sentia que os ex-combatentes eram vistos como pessoas que se fingiam de doentes para obter vantagens, e por isso se recusou a usar os benefícios da lei até 1926, quando sofreu um colapso nervoso e não teve outra escolha.

Apesar dessa hostilidade, a guerra permaneceu para Fred uma memória marcante. Ele casou-se no dia do aniversário de seu ferimento de guerra; deu à sua casa o nome dos lugares onde seus dois melhores companheiros foram enterrados; lembra-se (e cita) com detalhes os lugares e datas onde muitos de seus amigos foram mortos. Essas formas privadas de comemoração, que transformam a experiência grotesca em 
rituais e listas relativamente seguros, foram a maneira que Fred encontrou para lidar com o passado. As experiências e sentimentos com os quais ele não podia lidar eram expressos inconscientemente em seus sonhos:

"Bom, os sonhos que eu tive eram bombardeios, você sabe: estava numa trincheira ou num abrigo, sendo alvejado por tiros e bombas. E com muito medo, morrendo de medo. Eu não sabia que havia tantos outros como eu até eu ler esse livro sobre os Pozieres (Charlton, 1980). Muitos deles tinham esse medo, e se você pensar bem nisso, como poderia ser diferente? Você não sabe se o próximo morteiro que está vindo vai explodi-lo em pedacinhos ou deixá-lo tão estropriado que seria melhor que você tivesse sido explodido em pedaços... [No sonho] você passa por essa experiência e fica apavorado, tremendo de medo. Você morre de medo e pula da cama por causa dessa experiência."

Uma das razões pelas quais Fred não pôde pôr fim a seus pavores dos tempos de guerra e ao sentimento de inadequação é porque ele não conseguiu encontrar um reconhecimento público apropriado da sua experiência como soldado. Ele descobriu que não poderia falar sobre sua guerra:

"Bem, era uma atmosfera diferente nos anos 1920, por exemplo, e no começo dos anos 1930. Em primeiro lugar, os que estiveram na guerra relutavam em falar sobre ela, e os que não foram à guerra, as mulheres e outros, pareciam não querer ouvir. Então a guerra ficou escondida, pelo menos no que se refere às pessoas comuns... Eu nunca falava sobre isso. Nunca. Por anos e anos e anos. Porque foi assim eu não sei. Mas os soldados, em geral, não eram muito entusiasmados sobre a vida no exército e gostaram muito de voltar a usar roupas civis novamente... Quando voltamos, havia um tipo de hostilidade contra qualquer coisa que tivesse a ver com a guerra... Tudo o que queriam era a maior distância possível de tudo que tivesse a ver com o exército, a repatriação ou a guerra."

Fred trancafiou seu certificado de ex-combatente, ricamente emoldurado, em uma gaveta empoeirada; recusava-se a usar suas medalhas 
ou participar de paradas no dia do An₹ac ou de reuniões do batalhão. A natureza do dia do Anz̧ac e de outras formas públicas de comemoração e a negligência da parte do governo foram apontadas por Fred como responsáveis por sua incapacidade de exprimir ou resolver sua ambivalência quanto à sua experiência de guerra. Isso não era verdade para todos os diggers. Muitos dos homens que eu entrevistei descreveram como apreciavam a celebração de sua identidade digger no dia do Anzac, e tinham lembranças divertidas das reuniões de veteranos. A afirmação e a rememoração públicas ajudaram esses homens a lidar com seu passado, filtrando as memórias que eram pessoalmente dolorosas ou que contradissessem a lenda. A nascente lenda do Anzac funcionou porque muitos veteranos queriam e precisavam identificar-se com ela.

A explicação de Fred, em sua entrevista inicial, sobre sua não-participação é que o Dia do Anzac era uma grande bebedeira, e ele não era um beberrão. Ele reforça a sua própria sobriedade e reclama que a imagem popular do digger desordeiro - beberrão, jogador e mulherengo não descreve adequadamente sua própria experiência e visão da Força Imperial Australiana. Eu não esperava essa resposta, mas isso mostrou como outro aspecto do estereótipo digger - um desordeiro assim como um lutador - poderia representar erradamente a experiência de um indivíduo, exclui-lo dos rituais de afirmação pública, tornando-o inseguro quanto à sua própria identidade. Muitos outros velhos diggers expressaram o mesmo desconforto quanto à imagem de desordeiros que predominou nos recentes filmes sobre o Anzac, lembrando que mesmo durante a guerra eles se sentiam desconfortáveis com esse comportamento e reputação. Outros se identificaram com o estereótipo, que trouxe à lembrança memórias excitantes de sua própria juventude selvagem.

Fred também evitava o Dia do Anzac porque a retórica patriótica dessa comemoração não correspondia às suas dúvidas, no tempo da guerra, sobre a justiça do envolvimento australiano, ou à amargura que ele sentiu com o tratamento recebido pelos soldados após a guerra. Mas as principais razões para que ele não participasse dos rituais do Dia do Anzac eram a confusão e angústia extremas que sentia quando pensava na guerra. A celebração pública dos heróis do Anqac era uma lembrança dolorosa de sua própria inadequação como soldado e como homem, e Fred foi incapaz de desfrutar do consolo e da afirmação que a celebração ofereceu aos outros ex-combatentes. 
Apesar de Fred Farraw ter ficado traumatizado por suas memórias e identidade como Anzac através da década de 1920, gradualmente encontrou outra vida e identidade no movimento trabalhista, que, por sua vez, ajudou-o a compor um sentido para sua guerra com o qual ele poderia conviver mais facilmente. Fred lembra-se que estava politicamente confuso após a guerra, mas um colega de trabalho persuadiu-o a entrar no Sindicato dos Trabalhadores nas Indústrias de Vagões em 1923: "aquele foi o começo da minha participação ativa na política... e plantou a semente do socialismo que desenvolvi alguns anos depois e que mantive por toda minha vida". Ele tornou-se ativo no sindicato e filiou-se ao Partido Trabalhista (Labour Party) em 1926. Depois, desempregado e desiludido com o governo trabalhista de 1930, filiou-se ao Partido Comunista. No movimento trabalhista Fred encontrou camaradas que o apoiaram e gradualmente reconquistou sua autoconfiança. Seu novo grupo de companheiros - muitos dos quais eram ex-combatentes - e a leitura voraz de tratados radicais sobre a guerra ajudaramno a articular e definir sua experiência de guerra e a desilusão posterior. Ele acredita que isso foi verdade para muitos outros diggers e cita o exemplo de seu amigo Sid Norris:

"Quanto a isso, essa grande mudança, politicamente falando, o Sid foi um dos milhares de diggers que abandonaram suas crenças anteriores à guerra, de que Deus, o Rei e o Império valiam qualquer sacrifício. A experiência mais amarga que ocorre nas guerras é o fato de que poucas pessoas obtêm grandes lucros; isto é uma lição que mudou as idéias políticas dos diggers do conservadorismo para o radicalismo. Isso é uma parte da lenda do Anzac que nunca foi abordada pelos escritores da Grande Guerra. Talvez você possa dar alguma atenção a isso."

Apesar de Fred não ter feito estas constatações durante a guerra, no final dos anos 1920 sua nova compreensão política ajudou-o a enfatizar percepções particulares de sua experiência como soldado. Assim, Fred agora ironicamente enfatizava a história de um irlandês que trabalhava na fazenda de seu pai, que o tinha alertado para não lutar na guerra dos "homens ricos", e representava-se a si mesmo como uma vítima involuntária de uma guerra imperialista. Ele também reafirmava 
que a relação entre oficiais e soldados nas forças imperiais australianas não era tão diferente daquela que ocorria entre empregadores e trabalhadores na Austrália em tempo de paz, e que os diggers muitas vezes rebelavam-se contra a autoridade (ele se lembra de um incidente no qual ele e dois companheiros planejaram, sem sucesso, matar um oficial impopular). Essa compreensão da guerra era parte de uma tradição Anzac mais radical, defendida por alguns ativistas do novo movimento trabalhista (ver Fox, 1936). Como um defensor dessa tradição, Fred articulou sua desilusão quanto à repatriação e deduziu que o Dia do Anzac era uma "manobra inteligente" para reunir novamente os soldados e assim sufocar sua raiva quanto ao problema das pensões e do desemprego. [...]

Fred também se tornou cético quanto às organizações de ex-combatentes que controlavam o Dia do Anqac. Ele se lembra que os soldados nas trincheiras falavam sobre a necessidade de organizarem-se para exigir condições decentes após a guerra, e que ele aderiu à Liga Imperial Australiana dos Soldados e Marinheiros Retornados (Returned Sailor's and Soldier's Imperial League of Australia - RSSILA), agora a poderosa RSL, no dia em que foi desmobilizado. Mas a Liga foi criada e controlada por uma aliança de cidadãos e ex-combatentes conservadores, e conseguiu o reconhecimento do governo como o representante oficial dos ex-combatentes "em troco por defender os poderes constituídos" (estes excombatentes temiam a violência dos diggers insatisfeitos e a presença de grupos de pressão de veteranos mais radicais; ver Lake, 1988). No começo dos anos 1920, a confusão interna de Fred e suas limitações físicas provavelmente mantiveram-no longe dos encontros da Liga, mas sua alienação era agora confirmada pela desconfiança política:

"Em outras palavras, os oficiais ocupavam na vida civil, de alguma forma, as mesmas posições que ocupavam no exército. Não era uma organização no melhor interesse do digger comum. Era uma organização política de extrema direita e nela não havia lugar para ninguém que tivesse princípios democráticos."

Ao final dos anos 1920, Fred Farraw alinhou-se contra a Liga e lutava, com membros do Movimento dos Trabalhadores Desempregados (Unemployed Worker's Movement), liderado pelos comunistas, em batalhas de rua contra os homens da RSSILA e do movimento proto-fascista 
New Guard. Em 1937, ele se opunha à lenda oficial e aos representantes da RSSILA, tendo sido preso por distribuir panfletos pacifistas em uma parada, no Dia do Anzac.

Ironicamente, quando Fred tinha consolidado sua visão radical da guerra, a lenda do Anzac mais conservadora, elaborada pela RSSILA, que celebrava o triunfo da virilidade australiana e o batismo da nação, já estava bastante estabelecida. Os radicais contestavam essa versão da guerra - em Melbourne, por exemplo, alguns ex-combatentes protestaram contra o Santuário da Rememoração (Shrine of Remembrance), que iria glorificar a guerra, e fizeram uma campanha para um memorial mais útil, um hospital para os veteranos - mas por volta de 1930, os radicais perderam a batalha pela lenda; o rótulo "digger radical" havia se tornado uma contradição. Fred Farraw gradualmente deixou sua identidade de ex-combatente e assumiu o papel de "soldado do movimento trabalhista".

Embora a versão do movimento trabalhista sobre a guerra tenha ajudado Fred a sentir-se relativamente seguro com a análise da guerra como conseqüência de rivalidades imperiais e econômicas, e com a sua visão de si mesmo como uma vítima inocente e involuntária, essa versão não o ajudou (ou talvez não tenha podido ajudar) a exprimir ou resolver seus sentimentos pessoais traumáticos sobre a guerra. As teorias sobre os lucros da guerra deixavam-no irado, mas não o ajudavam a lidar com as memórias do terror, culpa ou inadequação. Da mesma forma, ele não podia apreciar a ampla afirmação pública do Dia do Anzac, que ajudava outros ex-combatentes a sentirem-se orgulhosos de seu serviço na guerra. Assim, por muitos anos, Fred simplesmente ignorou seu passado militar e tentou esquecer suas memórias dolorosas.

Há uma terceira fase na história de guerra de Fred Farraw. Em algum momento nos anos 1960 ou no começo de 1970, ele começou a ler e falar sobre a guerra fora do movimento trabalhista. Ele compareceu à cerimônia anual do Dia do Anqac de seu batalhão. Colocou suas insígnias de guerra na lapela, retirou seu certificado de ex-combatente da gaveta empoeirada em que se encontrava e pendurou-o na parede de sua sala (acima de uma foto mais recente dele mesmo como prefeito da municipalidade de Prahran, em Melbourne). Depois de anos de silêncio, Fred passou a falar longamente sobre a guerra para estudantes, cineastas e entrevistadores de história oral. Por quê? 
Fred explica a mudança de várias formas. É parcialmente o interesse renovado de um homem velho sobre a sua juventude: "Eu suponho que quando você fica velho, você tem um tipo de sentimento pelo que aconteceu muito tempo atrás". Ele também está apreciando o respeito, até mesmo a veneração, com a qual os poucos diggers remanescentes da Grande Guerra são tratados - tanto pelas pessoas comuns, que reconhecem a insígnia da Força Imperial Australiana, como pelos oficiais da Secretaria dos Veteranos (Veterans' Affairs), que lhes dizem que aquele emblema é uma "insígnia honrosa" e pagam seus crescentes custos médicos:

"Bem, houve um tempo em que não nos encaixávamos na figura de modo nenhum. Bem, nosso valor não foi reconhecido por muitos anos, então se agora há alguma coisa, mesmo que seja ter algum respeito, bem, eu acho que vale a pena."

Esses comentários aludem a processos mais gerais. Com o ressurgimento do interesse nos Anqacs, as experiências individuais específicas e muitas vezes contraditórias de veteranos estão sendo encobertas por uma versão generalizada, muitas vezes nostálgica, dos diggers e de sua guerra. Além disso, nessa elaboração moderna da lenda, aspectos da experiência de guerra que outrora foram tabus são agora aceitáveis publicamente. A guerra do Vietnã e a influência dos movimentos de paz alteraram as percepções públicas da guerra, tornando o soldado-vítima um tipo mais aceitável - embora ele ainda fique atrás em relação ao herói Anzac. Fred pode agora falar mais facilmente sobre sua experiência da "guerra como um inferno" e sobre o seu próprio sentimento de inadequação como soldado, porque esses aspectos da guerra são retratados nos livros e filmes históricos dos anos 1980. Ele elogia o modo como alguns recentes historiadores do An₹̧ac e diretores de televisão conseguiram reproduzir tão bem o horror e a degradação da guerra de trincheiras. O prazer pessoal de ter sua experiência como soldado reconhecida e afirmada depois de anos de alienação foi expresso vivamente quando perguntei a Fred sobre sua visita ao Memorial de Guerra (Australian War Memoria) em Camberra (a segunda principal atração turística da Austrália, perdendo apenas para a Sydney Opera House):

"Quase consegui um emprego ali. Estive lá há um ano e meio, você sabe, e foi a surpresa da minha vida... Fui tratado 
como um primo há muito tempo ausente [e me pediram para falar sobre of front ocidental para outros visitantes]. 'Bem', eu falei, 'eu não me importaria em fazer isso, mas eu trabalho pela paz e não pela guerra'. Um sujeito disse: 'Você sabe que este lugar foi construído como um memorial de paz, então você tem liberdade para exprimir suas opiniões sobre estas questões'... Então comecei... Bem, estive lá por dois ou três dias. Parecia que eu ia conseguir, com oitenta e tantos anos, um emprego permanente."

Não há dúvida que Fred trouxe vida às galerias com suas histórias da miséria da guerra de trincheiras - a chuva, a lama, os ratos, os piolhos, os morteiros, as explosões e o medo - e sentiu-se satisfeito, porque enfim a sua história da guerra estava sendo contada. E ele acreditou que estava passando uma mensagem de paz.

No entanto, nessa reconciliação profundamente importante com seu passado de guerra, e entre sua própria memória e a história pública dos Anzacs, a crítica política de Fred perdeu espaço. O Memorial de Guerra e os filmes de guerra admitem que para a pobre e infame infantaria, "a guerra é o inferno" - mesmo que eles ainda promovam o herói digger e a lenda do Anzac. Fred está tão satisfeito com o novo reconhecimento que não percebe que outros aspectos de sua experiência ainda são ignorados. Em sua discussão comigo, ele não considera como temas importantes as tensões entre oficiais e soldados na Força Imperial Australiana, a desilusão pós-guerra de muitos diggers, ou a análise da guerra como um negócio. Fred assume que qualquer museu retratando o horror do front ocidental é um "memorial de paz", mas não reconhece a ambigüidade política de um museu no qual pequenos garotos brincam sobre tanques e querem crescer para se tornarem soldados.

A memória de Fred, porém, guarda ainda um aspecto radical. Ele continua a condenar o patriotismo artificial do Dia do Anzac, e carrega suas medalhas de guerra nos encontros de paz do Domingo de Ramos, aproveitando o novo interesse nos Anzacs para fazer sua própria crítica da guerra e da sociedade australiana. Entretanto, ele não dirige essa crítica aos escritores e diretores de TV e cinema, os poderosos criadores de mitos dos nossos tempos. A efetividade da lenda do Anzac dos anos 1980 é que ela convence mesmo os diggers radicais, como Fred, fazendo-os crer que é sua história que está sendo contada, enquanto sutilmente 
reelabora o sentido conservador da guerra, do caráter nacional e da história australiana, adaptando-os aos anos 1980. O processo "hegemônico" parece similar ao que ocorreu com os diggers que aderiram à RSSILA e ao Dia do Anqac nos passados anos 1920. Em ambas as ocasiões, indivíduos foram incluídos e suas memórias reconhecidas, seletivamente, pelos rituais e significados públicos de rememoração. Essa afirmação pode ser essencial para a paz de espírito individual, porém nesse processo, memórias contraditórias e desafiadoras são descartadas ou reprimidas.

O estudo de caso de Fred Farraw ilumina a relação dinâmica entre a memória individual e o mito nacional, e sugere maneiras pelas quais a história oral pode ser mais do que apenas "a voz do passado". A história oral pode nos ajudar a compreender como e porque as mitologias nacionais funcionam (ou não) para indivíduos, e para a sociedade em geral. Também pode revelar as possibilidades e dificuldades em se desenvolver e sustentar memórias de oposição. Esta compreensão pode nos habilitar a participar mais efetivamente, como historiadores, na luta coletiva por versões mais democráticas e radicais do nosso passado e do nosso vir a ser.

\section{Referências bibliográficas:}

CHARLTON, P. Pozieres: Australians on the Somme. North Ryde, Meuthen Haynes, 1980.

FOX, L.F. The Truth about Anzac. Melbourne, Victorian Council Against War and Fascism, 1936.

JOHNSON, R. et. al. (eds.) Making Histoires; Studies in History Writing and Politics. London, Hutchinson, 1982.

LAKE, M. "The power of Anzac". In: McKERNAN, m \& BROWNE, M. (eds.) australia: Two Centuries of War and Peace". Camberra, Australian War Memorial/Allen \& Unwin, 1988. 
Resumo: Neste artigo Alistair Thomson trata das conexões entre memória individual e coletiva, mostrando como as lembranças de um veterano de Guerra australiano foram influenciadas por experiências pessoais subseqüentes e por mudanças nas comemorações públicas. A análise das camadas de significado encontradas nas memórias gravadas, não apenas ajuda-nos a entender o que aconteceu no passado, mas também pode mostrar como os significados dos eventos passados mudam com o tempo para os indivíduos e para a sociedade. O artigo mostra como memória e identidade são entrelaçadas. A identidade de Fred Farrall - como homem e como soldado - foi moldada pelas recordações de guerra; por outro lado, sua identidade pessoal afetou a maneira como ele se lembra da guerra.

PalaVras-Chave: Memória; História Oral; Guerra; Austrália.

Anzac Memories: Putting Popular Memory Theory into Practice in Australia ABSTRACT: In this article Alistair Thomson grapples with the interconnections between individual and collective memory, showing how the remembering of an Australian war veteran was influenced by subsequent personal experiences and by changes in public commemoration. Analysis of the layers of meaning which are threaded through recorded memories not only helps us to understand what happened in the past, but can also show how the meanings of past events have changed over time for individuals and in society. The article shows how memory and identity are inter-twined. Fred Farrall's identity - as a man and as a soldier was shaped by his war memories and, in turn, his changing personal identity affected how he was able to remember the war.

KEY WORDS: Memory; Oral History; War; Australia. 